GAPP, número 22, noviembre-abril de 2019

Sección: EXPERIENCIAS Y CASOS

Recibido: 13-11-2018

Modificado: 01-02-2019

Aceptado: 01-02-2019

DOI: 10.24965/gapp.i22.10603

Páginas: 120-139

\title{
La política pública de transporte de viajeros: el caso de la Entidad Pública del Transporte de la Región de Murcia
}

\section{The public politics of travelers' transport: the case of the Public Entity of the Transport of the Region of Murcia}

\author{
Saturnino Espín López \\ Administración Autonómica Región de Murcia (España) \\ ORCID: http://orcid.org/0000-0003-2449-2233 \\ saturespin@gmail.com
}

\section{NOTA BIOGRÁFICA}

Doctor en Ciencia Política y de la Administración por la Universidad de Murcia en el año 2017. Licenciado en Derecho por la Universidad de Murcia en el año 1995. Máster en Gobierno, Administración y Políticas Públicas por la Universidad de Murcia en el año 2013. Ingresó en la escala superior de técnicos de tráfico de la Administración General del Estado en el año 2000. También ha trabajado en la Administración Autonómica de la Región de Murcia desempeñando entre otros la Jefatura de la Inspección de Transportes. Actualmente presta servicio en la Confederación Hidrográfica del Segura.

\author{
Antonia González Salcedo \\ Universidad de Murcia (España) \\ ORCID: https://orcid.org/0000-0003-4868-6905 \\ agonzalez@um.es
}

\section{NOTA BIOGRÁFICA}

Doctora en Ciencia Política por la Universidad de Murcia. Licenciada en Ciencias Políticas y de la Administración por la Universidad de Granada, obteniendo Premio Extraordinario de Licenciatura y Premio Nacional Fin de Carrera. Es profesora Contratada Doctora de la Universidad de Murcia. Ha realizado estancias en Universidades e Institutos de prestigio, y cuenta con publicaciones en revistas españolas e internacionales de referencia.

\section{RESUMEN}

Las Relaciones Intergubernamentales son un factor constitutivo de la mayoría de las políticas públicas, también en el caso de la política del transporte, y su análisis ha permitido integrar el pluralismo institucional y territorial en el estudio de los procesos de decisión e implementación de políticas públicas, con el objeto de analizar el papel de los distintos actores y de sus mecanismos de interacción y articulación existentes. El objetivo de este artículo es analizar las causas que influyeron en la creación de la Entidad Pública del Transporte y evaluar su funcionamiento para conocer las razones que expliquen su desaparición prestando especial atención a la influencia de las Relaciones Intergubernamentales.

\section{PALABRAS CLAVE}

Política Transporte; políticas públicas; implementación; relaciones intergubernamentales; Región de Murcia. 


\begin{abstract}
The Intergovernmental Relations are a constitutive factor of the majority of the public policies, also in case of the politics of the transport, and his analysis has allowed to integrate the institutional and territorial pluralism in the study of the processes of decision and implementation of public policies, in order to analyze the paper of the different actors and of his existing mechanisms of interaction and joint. The aim of this article is to analyze the reasons that influenced the creation of the Public Entity of the Transport and to evaluate his functioning to know the reasons that explain his disappearance paying particular attention to the influence of the Intergovernmental Relations.
\end{abstract}

\title{
KEYWORDS
}

Politics Transports; Public policies; Implementation; Intergovernmental Relations; Region of Murcia.

\section{SUMARIO}

1. INTRODUCCIÓN. 2. APROXIMACIÓN TEÓRICA. 3. METODOLOGÍA. 4. RESULTADOS. 4.1. LA CREACIÓN DE LA EMPRESA PÚBLICA DE TRANSPORTE EN MURCIA. 4.2. LAS RIG COMO ORIGEN DEL DESENCUENTRO RESPECTO AL MODELO DE TRANSPORTE. 5. DISCUSIÓN: ¿POR QUÉ FALLÓ LA POLÍTICA DE TRANSPORTE EN LA REGIÓN DE MURCIA? 5.1. BUENA ESTRATEGIA DE COMUNICACIÓN PERO CONSENSO INSUFICIENTE. 5.2. AUSENCIA DE UNA PLANIFICACIÓN ESTRATÉGICA DE TRANSPORTES. 5.3. LA PRETENDIDA FLEXIBILIDAD EN SU CREACIÓN SE CONVIERTE EN IMPROVISACIÓN. 5.4. CARENCIA DE MEDIOS Y RECURSOS MATERIALES E INEXISTENCIA DE REPRESENTACIÓN PONDERADA ECONÓMICAMENTE EN SUS ÓRGANOS DE GOBIERNO. 5.5. MAL FUNCIONAMIENTO DE LAS RIG EN UNA RED DE ACTORES CONFLICTUAL. BIBLIOGRAFÍA.

\section{INTRODUCCIÓN}

La evolución del sistema de organización territorial del Estado Español ha llevado a la proliferación de diferentes niveles gubernamentales articulados en torno a un sistema de distribución competencial para las distintas administraciones Estatal, Autonómica, Provincial y Municipal que lo integran. Cuando cada una de estas administraciones actúa en ejercicio de su autonomía, ejerciendo las competencias que se les ha atribuido para poner en marcha las políticas públicas, lo hacen de manera exclusiva, pero también en ocasiones, de manera concurrente o compartida. En todos los casos, tomando decisiones y ejerciendo una u otra clase de competencias, lo hacen incidiendo en la esfera personal del ciudadano, que percibe la actividad de las administraciones resultado de la política pública desarrollada, en términos de una mayor o menor eficacia y calidad de los servicios públicos que se le ofrecen.

La Política de transporte de viajeros afecta a la vida diaria de los ciudadanos y se percibe con la consiguiente sensación de proximidad y cercanía, por lo que su eficacia es evaluada con parámetros de mayor exigencia que otras en el orden de prioridades particular de sus destinatarios. Por otra parte, tiene también una clara dimensión social. En este sentido, son numerosos los autores que han destacado la importancia y la repercusión del sector del transporte en la sociedad, en cuanto que tiene una clara incidencia en la evolución de las ciudades, en la calidad de vida de los ciudadanos, en la vertebración del territorio o en el medio ambiente, convirtiéndose en un evidente indicador del desarrollo económico de un país.

Las Relaciones Intergubernamentales ${ }^{1}$ son un factor constitutivo de la mayoría de las políticas públicas, también en el caso de la política del transporte, y su análisis ha permitido integrar el pluralismo institucional y territorial en el estudio de los procesos de decisión e implementación de políticas públicas, con el objeto de analizar el papel de los distintos actores y de sus mecanismos de interacción y articulación existentes.

\section{APROXIMACIÓN TEÓRICA}

Existen varios estudios acerca de las RIG, que tratan directamente el problema de la implementación y que permiten identificar los problemas de las relaciones en y entre las organizaciones. Algunos de esos estudios son los de Bailey y Mosher (1968), Sundquist (1969), Derthick (1970, 1972), Pressman y Wildavsky (1973). Es-

\footnotetext{
1 En adelante RIG.
} 
tas obras ofrecen diversas perspectivas sobre los conflictos entre funcionarios nacionales, estatales y locales, y señalan la interdependencia de los funcionarios públicos en todos los niveles del gobierno. Además, y esto es lo más importante, identifican los factores que perturban el proceso de implementación en organizaciones que no están ni bien integradas ni autocontenidas. Por ello, insisten en la autonomía de los subordinados, tanto por lo que se refiere al tratamiento de los asuntos internos como al de los interorganizacionales.

La implementación de políticas públicas requiere la acción conjunta de diversas organizaciones. Las redes de política pública deben ser pivotes que desencadenan procesos que otorgan mayor poder para los ciudadanos conforme a los niveles o sectores en donde se demuestre tener capacidad de gestión y autonomía (Chaqués, 2004). Sin embargo, las investigaciones sobre la implementación, han puesto de manifiesto como los problemas analíticos y prácticos más interesantes son los que se refieren a contextos que involucran a diversos actores y a distintas organizaciones y no los que se refieren a una única entidad responsable de la implementación. Así, en el caso de la resolución de problemas públicos complicados, como podría tratarse del transporte, a veces relacionados con otros problemas adicionales, o en espacios políticos densos donde es frecuente que la autoridad sea compartida por diversas unidades, suelen participar diversas organizaciones.

En estos espacios en los que los investigadores han intentado establecer pautas teóricas sobre el papel de la implementación, y aún no existiendo consenso entre los principios que deberían regir una teoría de la implementación ni sobre las variables cruciales para el éxito del proceso, es posible sistematizar de manera resumida las variables que O'Toole (2000) considera importantes para el estudio de la misma.

Aproximadamente la mitad de los estudios publicados identifican como variables significativas las características de la política misma (claridad, especificidad y/o flexibilidad de las metas y los procedimientos, y la validez de la teoría causan de la política) aproximadamente la misma proporción de estudios aducen que los recursos son determinantes y finalmente otras variables son, los actores responsables de la implementación o de las estructuras que abarcan una multiplicidad de actores, el número de actores involucrados o las actitudes y percepciones del personal responsable de la implementación.

Con independencia de que se profundice en algunas de ellas durante la realización del estudio, podemos apuntar ahora que Menzel (1981) identifica como variables «los límites de tiempo impuestos por el estatuto, la configuración de las RIG, las relaciones de apoyo entre los electores, estructura y administración de las organizaciones, reglas, estilos de coerción y la oportunidad». Van Meter y Van Horn (1975) señalan cuatro factores determinantes en el proceso de implementación, que podrían también tener su influencia en la política de transporte objeto de estudio: a) la comunicación entre las organizaciones y las actividades de inducción, b) las características de las agencias responsables de la implementación, c) la influencia del ambiente económico, social y político sobre la organización donde la implementación tiene lugar y d) la disposición de los encargados de la misma.

Igualmente O'Toole identifica una serie de recomendaciones prácticas que los estudios de investigación sobre implementación han planteado, entre las que podríamos destacar por estar relacionadas con el objeto de estudio, las formuladas por Hjern y Porter (1981) cuando señalan que «aunque es necesario adoptar una perspectiva legalista, la estructuración de las relaciones entre las organizaciones es una condición indispensable para el análisis de la implementación». También las formuladas por Molnar y Rogers (1979) en el sentido de «evitar una coordinación jerárquica simplista, y hacer énfasis en las relaciones colaterales e informales, concediendo importancia a la diversidad». Finalmente, Menzel (1981) destaca que hay que «evitar los plazos estatutarios rígidos que puedan impedir la implementación. Es preciso tomar en consideración la configuración de las RIG y/o interinstitucionales al diseñar la política. Es necesario generar relaciones de apoyo mutuo entre los diversos grupos de beneficiarios involucrados».

Y es que no sólo el marco formal y legal-constitucional de las normas y objetivos, así como los principios que rigen la cooperación entre los órganos verticales y horizontales en los que se ponen en práctica las RIG son determinantes en la implementación de la política de transportes, sino también factores como los recursos, las condiciones económicas, sociales y políticas, o las características de las instancias responsables de la implementación. En este sentido cobra importancia, el papel de los partidos políticos y sus organizaciones internas descentralizadas en las RIG. El papel de las oligarquías y poliarquías en la organización de los partidos y su traslación al implementar las políticas de transportes por los gobiernos.

También la actitud de los encargados de la implementación de la política, o la comunicación entre organizaciones es otro elemento a tener en cuenta pues permitirá a las autoridades incrementar la probabilidad de que los responsables de la implementación actúen de acuerdo con las normas y objetivos de la política.

Aunque con existencia más breve de lo deseable, la creación de la EPT en la Región de Murcia, es la experiencia que será objeto de estudio en este trabajo, como hemos destacado. En consonancia con la nueva forma 
de gobernar que implica, el concepto de gobernanza, puede ser valorado como ejemplo para la consecución del objetivo de cooperación interadministrativa, sin embargo como veremos, son diversas las opiniones en cuanto a si el diseño del ámbito territorial de acción ha sido el más adecuado para dirigir las actuaciones hacia el fin mediato de garantizar el derecho a la movilidad de la ciudadanía con un alto grado de sostenibilidad y calidad.

Como indican Lowi (1964) y Froman (1968) a diferentes tipos de decisión corresponden determinados procesos, estructuras y relaciones entre los factores que influyen en la ejecución de la política pública. Es posible sin embargo clasificar las políticas en función de dos características relacionadas con las metas y objetivos y que están presentes en la mayoría de ellas: en primer lugar, la magnitud del cambio requerido. Los grandes cambios tienen menos posibilidades de producir respuestas positivas que los cambios graduales acumulativos. En este sentido algunos autores como Kaufman (1971), destacan que la implementación será efectiva cuando no se exija a la dependencia pública responsable ninguna reorganización drástica. En segundo lugar, el grado de conflicto o consenso en torno a la consecución de metas y objetivos, identificando Gross (1971) la participación como uno de los factores que condiciona el consenso en torno a las metas, afectando en consecuencia a la participación.

En función de estas dos características, es posible hablar por un lado de políticas con grandes cambios y consenso bajo y por otra parte de políticas con cambios menores y consenso alto. En estas últimas la implementación tiene mayores probabilidades de éxito. Cabe preguntarse si la influencia de las RIG en la ejecución de la política de transportes responde a esta disyuntiva. El análisis del objeto de estudio, con un caso como el de la creación y desaparición de la EPT, nos permitirá contrastar empíricamente la naturaleza de este cambio y el grado de consenso.

\section{METODOLOGÍA}

Como estrategia de investigación para el estudio de la cuestión problematizada, se utiliza el estudio del caso. Los estudios de caso constituyen una estrategia de investigación frecuente en la Ciencia Política (Anduiza, 2009, pág. 69) y se caracterizan por investigar una única unidad de análisis, de la que analizan muchas propiedades en un único momento en el tiempo, por lo que la mayoría son estudios diacrónicos, un solo caso, con evolución en el tiempo, analizando la «foto fija» del momento, y teniendo escaso valor las terceras variables. Se trata de estudios basados en una única observación para cada variable relativa a la unidad de análisis sin considerar variables temporales ni espaciales. En nuestra investigación, el estudio de caso consistirá en el estudio de una unidad de análisis desde la perspectiva diacrónica, teniendo en cuenta la evolución temporal de la unidad de análisis.

Aún no pretendiendo obtener conclusiones generalizables, sí se pretende con el análisis de la EPT conocer si las RIG pudieron tener influencia en su funcionamiento como órgano de concentración de competencias. Se pretende identificar las variables que influyeron en la EPT, para poner a prueba la teoría según la cual, en la política de transportes regional, y en concreto en la decisión de creación de la EPT y en su posterior desaparición, de entre las distintas variables, las RIG influyen como variable independiente, para a continuación validarla o refutarla y ponerla en cuestión. Cuando se utiliza la estrategia de estudio de caso, para generar hipótesis o con la finalidad de verificar teorías ya establecidas, el estudio de caso sirve para complementar una investigación comparada, proporcionando ideas y desarrollando hipótesis.

Por otra parte, debemos preguntarnos por cómo seleccionar los casos en los estudios de carácter cualitativo como el que nos ocupa, en el que por sus propias características, el estudio se referirá como decimos a un solo caso, aunque con gran profundidad y nivel de detalle. La selección revestirá gran importancia en este supuesto ya que de ella dependerá que se pueda estar razonablemente seguro de que los resultados obtenidos no sean un artificio provocado por una selección sesgada de los casos analizados (Santana, 2013, pág. 136).

La creación de la EPT como órgano de concentración de competencias y aspecto troncal de la política de transporte de viajeros en Murcia, es además, un caso de gran relevancia y repercusión social y así se destacó en la Asamblea Regional cuando en el debate sobre la actuación política del Consejo de Gobierno en Junio de 2005, el presidente del gobierno regional hizo especial énfasis en la creación de la EPT.

En el estudio se utilizarán técnicas cualitativas como el empleo de entrevistas en profundidad semiestructuradas, que nos permitirán tener conocimiento de la realidad acaecida en la fase de formulación de las políticas públicas. Mientras que en la investigación cuantitativa la operacionalización de los conceptos juega un papel determinante para la transformación de las hipótesis teóricas en proposiciones empíricamente controlables, en el presente trabajo se utilizarán conceptos de investigación cualitativa entendidos, es decir, marcos 
de referencia abiertos que tienen el objetivo de orientar al investigador, hacerle más sensible a temas y problemas determinados en el curso de la entrevista, que están exentos del carácter de articulación, explicación y definición que en cambio se exige en la intención de operacionalizarlos que tiene el investigador cuantitativo.

La información utilizada en este artículo procede tanto de datos primarios, obtenidos de las entrevistas en profundidad realizadas a actores políticos y otros grupos de interés como concesionarios y técnicos de la administración, como de datos secundarios obtenidos de las Administraciones Central y Autonómica, y de la base de datos del CIS. En este sentido, se han utilizado técnicas estadísticas con datos secundarios, para conocer los escenarios que concurrieron en su momento, y que posiblemente propiciaron la adopción de dichas políticas públicas.

Así mismo, durante este trabajo se han empleado herramientas de la observación y análisis documental, que incluyen la revisión bibliográfica de diferentes documentos, así como la consulta y análisis de normativa. Por otra parte, también se han trabajado las bases de datos de diversos trabajos elaborados por la EPT, empleando tablas de contingencia para describir la situación del sector del transporte público de viajeros. Se analizan así mismo, los debates parlamentarios que tuvieron lugar cuando se adoptaron las políticas públicas de transporte de viajeros.

\section{ACTORES POLÍTICO INSTITUCIONALES Y GRUPOS DE INTERÉS ENTREVISTADOS}

Marcos Antonio Nogueroles Pérez, Diputado en la VI Legislatura de la Asamblea Regional (2003-2007) por el grupo parlamentario popular, en la que se creó la EPT.

Francisco Oñate Marín, Diputado en la VI Legislatura de la Asamblea Regional (2003-2007) por el grupo parlamentario socialista, en la que se creó la EPT. A su condición de actual senador y participante en la política de transportes como diputado regional durante el periodo de 2007 a 2012, el de mayor actividad de la EPT, une la de exconcejal del Ayuntamiento de Murcia hasta el año 2003.

Cayetano Jaime Moltó, Diputado en la VI Legislatura de la Asamblea Regional (2003-2007) por el grupo parlamentario Mixto (Izquierda Unida), en la que se creó la EPT.

Antonio Castillo Pérez, Concejal de Transportes del Ayuntamiento de Murcia durante la legislatura de 2007-2011.

Alfonso Navarro Gavilán, Diputado en la VI Legislatura de la Asamblea Regional (2003-2007) por el grupo parlamentario socialista, en la que se creó la EPT. Concejal del Ayuntamiento de Murcia y portavoz del grupo municipal socialista durante 2010 a 2012.

Esther Herguedas Aparicio, Concejal del grupo municipal de Izquierda Unida en el Ayuntamiento de Murcia durante las legislaturas de 2007 y 2011.

José Luis Sánchez Ruiz, Director Gerente de LATBUS, une la de Presidente de FENEBÚS-Murcia.

José Antonio Pacheco Méndez, Responsable jurídico y de contratación de la EPT desde 2008 hasta su desaparición en 2012.

Eduardo Contreras Linares, Alcalde de Molina de Segura (Partido Popular) desde 1995 a 2016.

Asociación de consumidores «Thader».

Asociación Murciana de Consumidores y Usuarios «Consumur».

\section{RESULTADOS}

\subsection{La creación de la Empresa Pública de Transporte en Murcia}

El objetivo de la ley de creación de la EPT era «coordinar las actuaciones en materia de transporte urbano» de manera que gran parte de las actuaciones estaban orientadas a impulsar y reforzar la cooperación con las corporaciones locales. Es claro y meridiano que a mayor población, el esfuerzo de la EPT en impulsar la cooperación debiera de ser mayor, sin embargo, los esfuerzos de coordinación no siempre se han producido respecto a ayuntamientos con mayor número de población, y en consecuencia con los que mayores problemas de transporte presentan al concentrar mayor número de desplazamientos. 
En los primeros años de la EPT el liderazgo no está claro, y a veces es la propia Dirección General de Transportes y Puertos la que asume el protagonismo al conceder subvenciones. Cuando en Octubre de 2008 se decide otorgar subvenciones no fue el criterio demográfico el prioritario, ya que estas ayudas fueron destinadas a conectar pedanías con pocos habitantes. Otro aspecto destacable es que de los diez Ayuntamientos subvencionados en tan sólo en uno de ellos (Moratalla) gobierna un partido distinto al que gobierna en la región, y ello a pesar de que en 2008 un $26 \%$ de los Ayuntamientos de la región, correspondían a partidos distintos al del gobierno regional. También ese mismo año 2008 se otorgaron $1.310 .000 €$ para construcción de carriles bici y planes de movilidad urbana aplicándose el mismo criterio, si bien en esta ocasión eran diez de un total de dieciséis, los ayuntamientos con distinto color político.

Por tanto, durante la etapa de implementación «ejecutiva» no se atiende suficientemente a variables de contexto como el número de habitantes, sino que parece que priman variables de carácter político. El diputado regional Jaime Moltó, va más allá de las RIG para explicar la decisión de creación de la EPT y habla de relaciones de partido cuando señala que «lo que hubo fue una traslación de la relación de poder en el partido que gobernaba la Región: Secretario General (Alcalde de Murcia), Presidente (del partido y del gobierno regional)» Se refiere a una traslación de la relación del partido a la relación en los cargos de la EPT cuyo presidente era el consejero y el vicepresidente primero el alcalde Cámara, y añade «más que las RIG las que provocaron su impulso fueron de compromisos para con inversores y desarrollos urbanísticos. Realizadas las inversiones, el Ente no tenía sentido, ya que los costes de operatividad son asumidos por las corporaciones locales, si bien disponen de desigual subvención autonómica».

Por ejemplo, las RIG del Ayuntamiento de Murcia con la EPT atravesaron altibajos, pero no cabe duda de que al menos durante el primer trienio, gobernando Miguel Ángel Cámara en el Ayuntamiento y Ramón Luis Valcárcel a nivel regional, el entendimiento inicial que existía entre ambos en otros tiempos, empezaba a resquebrajarse, lo que pudo afectar a que no se tuviera en cuenta la proporción entre número de habitantes. Fruto de la reunión en Mayo de 2007 entre los alcaldes del área metropolitana Murcia, Molina y Alcantarilla, se acuerda crear una comisión de técnicos para elaborar un estudio de viabilidad previo a la licitación del tranvía que una a esos tres municipios, pero en Agosto Ballesta entra en el proyecto del tranvía y se reúne con los concejales de transporte de Murcia (no acude el Alcalde Cámara) y el alcalde de Molina, este último tan interesado que pidió expresamente el apoyo del presidente regional. Incluso se plantea desde la consejería ampliar el proyecto a Las Torres de Cotillas. Desde el ayuntamiento también en el mes de Agosto se pone de manifiesto que va a dejar de subvencionar las líneas interurbanas intramunicipales (cuya titularidad corresponde a la CARM) pues tan solo le corresponde gestionar las seis urbanas, y por ellas ya asume un gasto seis veces superior al de la región, y finalmente el presidente regional interviene para afirmar que «en el año 2010 el tranvía unirá la capital con las ciudades más próximas, como Molina de Segura, Alguazas, Torres de Cotillas, Alcantarilla y El Palmar, además de La Arrixaca y el Campus de Espinardo». Posteriormente el nuevo Director de la EPT, José Guillén, afirmará en su toma de posesión que «apoya la ampliación del tranvía».

Aunque el Estado sigue siendo el articulador societal de las políticas públicas, la división entre lo público y lo privado es cada vez más difusa, siendo preciso otro tipo de gobierno que genere propicie la participación de una diversidad de actores, en consecuencia, la implementación de políticas públicas implica en cierta medida también una metamorfosis institucional, una burocratización de la política, como la que tiene lugar con la creación de organismos de concentración de competencias.

La política que llevó a la creación de la EPT gozó de un consenso serio, pues se admitía la necesidad de crear una autoridad común de transporte, y en el proceso de toma de decisiones se generaban alternativas, o se discutía cual debía ser su forma, pero no se discutía la existencia de la EPT. Se especifican sus metas y objetivos. Se tienen los recursos apropiados, el «estatuto» o norma legal de creación es preciso, hay prisas por crear la EPT, ya que en todas las áreas metropolitanas existe una autoridad común del transporte y Murcia no puede ser menos, y la oposición como vimos en el proceso de participación en el debate político fue prácticamente inexistente. Produce pues sorpresa que se malogre, y que como veremos tan solo tenga una existencia «neta» de dos años (2009-2011).

Por tanto, hay un impulso a la búsqueda de solución, pero no podemos quedarnos en la descripción del fracaso para encontrar la solución al problema. Precisamente lo normal es lo difícil, no es lo que se produce por la mera inercia, sino que cuesta que una estrategia de creación, se despliegue «ordinariamente» sin que tenga intervención ninguna circunstancia insólita y en el caso de la EPT la hubo. La política de la creación de la EPT presentaba cierta ambigüedad en sus objetivos motivada por la necesidad de dotarla de carácter flexible. Esto en opinión del actual Senador Oñate le confirió cierta vulnerabilidad como lo demuestra el hecho de su fácil supresión: "si un órgano que desde el punto de vista objetivo se ve tan necesario hubiese tenido todas las 
condiciones de herramientas jurídicas, de aceptación por parte de los organismos a coordinar, de acierto en las decisiones que se hubiesen ido tomando, si todo eso hubiese estado digamos de sobresaliente, se hubiera hecho un órgano imposible de suprimir y sin embargo se suprimió y se suprimió sin demasiada polémica».

La implementación ordinaria de una estrategia como la de la EPT, con el déficit apuntado de participación como se ha expuesto, es lo verdaderamente difícil y en su evolución lo podemos observar. Sobre la falta de participación también se pronuncia el diputado Moltó para referirla concretamente a la fase de decisión indicando que "La fase de decisión fue parcial. Pues se abordó sin la necesaria participación de los operadores públicos y privados, tanto estatales como locales. La intermodalidad fue ignorada en su práctica (...) el Transporte por carretera absorbió el debate y recursos de un debate más amplio».

El alcalde de Molina, Eduardo Contreras, también considera insuficiente la incorporación de los municipios cercanos como Alcantarilla o Molina en el proceso consultivo inicial, quedando también bastante al margen la Federación de Municipios. Parece que el diseño de arriba hacia abajo encontró bastantes dificultades, al implementar una política en la que debían implicarse actores que no habían sido correctamente involucrados en el proceso decisorio.

En el análisis de entrevistas se admite que la creación de la EPT es una buena idea. Por ejemplo el presidente de «CONSUMUR» considera que «Un instrumento de coordinación como éste, resultaba necesario. Por tanto, la decisión de su creación era necesaria». Por tanto, se reconoce la pertinencia de su creación, pero nada más, porque se critica casi unánimemente la implementación, con las excepciones del Presidente de FENEBUS que afirma que «Existió una estrecha coordinación entre el Sector y la Administración en ambas etapas.» y del técnico de la EPT, que admite que se hubiera conseguido una mayor presencia si se hubiera dispuesto de mayor presupuesto, "Si a la EPT se le hubiese dotado, desde el primer momento, de un presupuesto acorde a la finalidad y objetivo que con la misma se pretendía alcanzar, los resultados se hubieran hecho palpables rápidamente» refiriéndose ambos a la implementación.

Incluso se critica también la forma de diseñar la decisión, cuando el diputado Navarro señala que la fase de decisión "como un proceso anárquico, desordenado y exento de sentido común (...)» y que "Se desaprovechó la ocasión para configurar un auténtico órgano de cooperación entre las Administraciones en materia de Transportes. (...) sin haber hecho previamente un análisis profundo de la situación de la Ordenación del Transporte Terrestre. Cuando se aprobó la creación de la EPT no existía una ley de Ordenación de Transporte Terrestre en la Región».

\subsection{Las RIG como origen del desencuentro respecto al modelo de transporte}

Durante su primer trienio de vida, 2006-2009, la EPT se comporta como un foro de debate sin proyección pragmática alguna, en la que se pasa de una estrategia top down de lo que parecía una decisión sólidamente fundada con la creación mediante la Ley $3 / 2006$, a una estrategia bottom up, cuando tras esa creación no hay nada detrás más que el resultado de la creación de un ente «fantasma». Como se puso de relieve al formular la política, siendo el transporte una materia en la que campa a sus anchas la concurrencia competencial de distintos niveles gubernamentales, lo que planteó no pocos problemas de consolidación legal y jurisprudencial, se lanzó una ley de creación pero no se esperó a contar con una ley que fundamentara las competencias de los niveles de gobierno regional y local, es decir, hay norma para la creación de una autoridad común, pero no hay norma para la fundamentación de las funciones que se van a atribuir a ese Ente Regional. Ni siquiera hay un grupo de trabajo que estudie con rigor técnico cómo canalizar el juego de fuerzas entre los ámbitos competenciales regional y local que operan en los órganos de gobierno de la EPT.

Durante el segundo trienio se llevó a cabo la asignación de recursos, disponiéndose de una partida presupuestaria que se destina a la realización de objetivos. Es la etapa en la que se pasa a la acción, en la que con sendas órdenes de Marzo y Diciembre de 2010, se adoptan diversas iniciativas para favorecer la eficacia del transporte y para fomentar su uso. Se corresponde con los años comprendidos entre 2010 y 2012 . Acción al menos en la práctica, pues en opinión del senador Oñate, el carácter deliberativo de la entidad siempre estuvo presente en la implementación y "es lo que lo hizo un órgano tan vulnerable, en un órgano que podía aconsejar, pero no podía imponer, y bueno... sabemos cómo es la administración, aquí cada uno le gusta ser autoridad en su territorio».

Asistimos en consecuencia a una demora en la implementación de la estrategia de creación y funcionamiento efectivo de la EPT. Como indica Cruz (1999), toda decisión y ejecución tienen una dimensión temporal. Las políticas, al enfrentarse a las restricciones impuestas por el entorno, al cambio de prioridades de los grupos demandantes-afectados, comportamientos adversos de los burócratas encargados de ejecutar 
celularmente la política, o incluso a la modificación de la orientación general del gobierno en turno, cambios ocurridos al interior de las características constitutivas del problema público, así como situaciones imprevistas, determinan en mucho cómo una política diseñada y decidida con «el mejor» curso de acción, puede no ser ejecutada según lo previsto. Una política, la de creación de la EPT, que se diseña en 2006 y que sin embargo no entra en funcionamiento efectivo hasta el 2009, y formalmente hasta el 2010 como veremos con el traspaso «efectivo» de funciones.

Dentro del segundo trienio correspondiente a la implementación ejecutiva, el año 2011 se inicia con un remanente de ejercicios anteriores por importe de 678.820,21€, resultante de la compensación del exceso del gasto corriente con base a el defecto de gasto en subvenciones de capital, y la Ley de Presupuestos Regional para 2011 asigna a la EPT un total de 5.139.500€ en concepto de subvenciones corrientes.

En primer lugar la norma presupuestaria no incluye en el presupuesto administrativo de la EPT publicado en el BORM núm. 301, la cuantía de las subvenciones de capital, y sólo contempla los ingresos y gastos de las operaciones corrientes. Esta necesidad se detecta a la vista del informe de auditoría que expresamente indica que la EPT ha recibido subvenciones de capital durante 2011 por importe de $750.000 €$. Sin embargo, a la vista del presupuesto publicado para 2012, que hace referencia al de 2011, tampoco esa cifra sería correcta y la cuantía que realmente se destinó a subvenciones de capital en la EPT en 2011 fue de 1.000.000€.

También hay errores en las cifras de operaciones corrientes. El informe indica que la EPT ha recibido subvenciones corrientes por importe de 4.139.500€, un millón menos de lo presupuestado. Además indica que los gastos corrientes han sido de $864.633,44 €$, cuantía superior a la prevista en el presupuesto publicado que es de $760.500 €$, pero que en uno y otro caso supone para 2011 un aumento de los gastos de personal, concretamente del $8,47 \%$ si atendemos a las cifras publicadas en el diario oficial. También atendiendo lo allí publicado, hay un aumento de los medios materiales del 32,34\%.

Estas divergencias en las cifras de subvenciones de capital, de las que directamente se olvida la Ley de presupuestos de 2011, y que tras el análisis se sitúa realmente en 1.000.000€, son consecuencia probablemente de los errores en el presupuesto respecto a las subvenciones corrientes, $5.139 .500 €$, un millón más de lo que realmente percibe la EPT en 2011.

Pero partiendo de ese importe real de 4.139.500€, la EPT concede subvenciones a LATBUS por importe de $3.442 .480,94 €$ y al Plan «Papi» por importe de $20.536,88 €$. La subvención de LATBUS deriva del contrato programa de 3 de Diciembre para la implantación del Unibono Municipal que establece un máximo anual de 1.738.123,39€, según se indica en el informe "como compensación por el impacto económico y la disminución de ingresos que el nuevo sistema tarifario pueda suponer en el conjunto de la explotación de las concesiones MUR-092, MUR-093 (interurbanas regionales) y la concesión de titularidad municipal (interurbanas intramunicipales del Ayuntamiento)».

Sin embargo, ese importe se supera hasta los $3.442 .480,94 €$ por que tras la reunión de la Comisión Mixta del Contrato Programa de 21 de Julio se afirma que el Ayuntamiento ha reducido las subvenciones para las concesiones municipales, pasando de casi nueve millones a cinco doscientos mil, con lo que para no repercutir esa cantidad en el usuario y que el logro del unibono municipal flamantemente conseguido por la EPT no diera al traste, se acuerda abonar al grupo LATBUS 2.880.479,50€ adicionales a las cantidades ya previstas en el contrato programa. Las cantidades, como en el caso del contrato programa y las reuniones de la comisión mixta, se abonan en el seno de unas reuniones bilaterales entre las administraciones regional y el grupo LATBUS por lo que en consecuencia, no se debaten en el foro de los órganos de gobierno de la EPT. No se debate en el Consejo de Administración, pero tampoco en el Consejo Asesor, pues ni siquiera estaba constituido al no existir los Estatutos.

Este acuerdo aparte de en la Comisión Mixta, se fraguó mediante reuniones con el Concejal de Transportes del Ayuntamiento de Murcia, ya que, según destaca en la entrevista con él mantenida, respondiendo a otra pregunta sobre si otros factores aparte de las RIG influyeron en la creación y desaparición de la EPT, señala que se llegó a un acuerdo entre Ayuntamiento y CARM para que asumieran cada administración el $50 \%$ del déficit de tarifa de LATBUS, incluyendo líneas municipales.

Aparte de las Relaciones Intergubernamentales, ¿Valora Vd. algún factor que influyese en su creación? ¿Y en su desaparición?

Bueno, durante mi mandato empezaba a asomar la crisis económica, pero no creo que influyera tanto la crisis en su desaparición como la falta de dotación económica para su funcionamiento. Me explico... las concesiones urbanas siguen hoy en día subvencionándose, no sé concretamente si por la administración regional, o por el Ayuntamiento, pero siguen recibiendo dinero público. 
No digo que la falta de dotación económica no viniera motivada por la crisis, que también, sino que considero decisiva la irrupción del tranvía, un medio de transporte que costaba al Ayuntamiento 10 millones de euros anuales, y que había que financiar sin dejar de lado a las concesiones urbanas, de manera que el tranvía absorbía casi todas las posibilidades de financiación. Por eso, Cámara quería que la Comunidad Autónoma contribuyese a hacer frente a ese déficit, quería no slo que contribuyese con el $50 \%$ de la financiación de la concesión urbana, (algo que conseguimos tras negociar con ellos) sino que quería además que ese $50 \%$ fuese extensivo también al tranvía, algo a lo que se negaron en la Comunidad Autónoma, al ser un proyecto municipal tal y como se diseñó.

Esta respuesta pone de manifiesto por una parte, que el cumplimiento del contrato programa que, en cuanto a financiación, señalaba claramente que el transporte público en el municipio de Murcia cuesta 10.479.082,39€ de los cuales el Ayuntamiento pone 8.390.959€ mientras que la CARM pone 2.088.123,39€, se asume por las administraciones municipal y regional al $50 \%$, lo que resulta corroborado por el informe de auditoría y los medios de comunicación que destacan la noticia en plena «batalla intergubernamental», asumiendo la EPT un importe de 3.742.480,94€ adicional al inicialmente previsto, si bien 300.000€ se pagarán a LATBUS en 2012. Simultáneamente las dificultades económicas de LATBUS continúan y entra en concurso voluntario de acreedores.

Pero además, y lo que es más importante para esta investigación, junto al juego de otras variables que por el contexto económico de crisis, podrían haber influido en el funcionamiento de la EPT, y en consecuencia a la larga en la eficacia del transporte, se destaca la importancia decisiva que tuvieron las RIG en el triángulo de actores privados, regionales, y locales, para el cumplimiento de los objetivos de la EPT en cuanto a coordinación se refiere, ya que este acuerdo supuso varias cosas:

- En primer lugar, teniendo en cuenta la composición monocolor del parlamento no sólo en la etapa de creación de la EPT sino también ahora durante su funcionamiento, la ausencia de conflictos entre partidos a nivel parlamentario se desplazó a la organización interna del partido hegemónico tanto a nivel regional como local, con disputas oligárquicas que se llevaron al terreno institucional en forma de desacuerdos sobre el apoyo presupuestario al grupo LATBUS, que recordemos era la concesionaria por excelencia tanto a nivel regional como local.

El alcalde Cámara sabía que el tranvía y su proyecto conllevaba un importante esfuerzo para las arcas del Ayuntamiento, y necesitaba que la CARM se implicara económicamente, pero en esa disputa oligárquica se siente respaldado y con fuerza para forzar situaciones límite, pues en el barómetro de elecciones locales para 2011 «Ciudad de Murcia» elaborado por el CEMOP, refuerza su liderazgo manteniendo su buena imagen entre los murcianos tras 16 años de gobierno en el Ayuntamiento, con una nota media que supera el aprobado (5,3 en general y un 6,8 entre los votantes del PP). Además, un $95 \%$ de los entrevistados lo conocen y consideran que su gestión es buena o muy buena por el $46,1 \%$ de los entrevistados.

Sin embargo, tenía el terreno electoral allanado, pero no el de las RIG con el Ayuntamiento, y el llamamiento para que la CARM (EPT) asumiera el $50 \%$ acordado también respecto al tranvía, fue respondido con una clara negativa por el Consejero, lo que llevó incluso a que el Director Gerente formulase posteriormente alegaciones críticas al contenido del PMUS realizado por el Ayuntamiento y al modelo del transporte que giraba una vez más en torno al tranvía.

- En segundo lugar, supuso que el tranvía, pieza importante en el juego de las RIG como señalamos, fuera un tranvía localista, en vez de metropolitano, como le hubiera gustado incluso a algunos responsables municipales entrevistados.

- Y en tercer lugar, ese desencuentro respecto al modelo de transporte entre los responsables autonómicos y municipal, fue ya insalvable en lo sucesivo y supuso un punto de inflexión en la trayectoria de la EPT dando al traste con su proyecto estrella «Unibono Regional», que pretendía conseguir el objetivo establecido por la Ley referente al marco tarifario común. La falta de acuerdo se trasladó también a las instituciones, como reconoce incluso el presidente de FENEBUS-Murcia al ser preguntado sobre si cree que las RIG influyeron en la desaparición de la EPT, destacando que "La crisis económica provocó, básicamente, la desaparición de la EPT, al igual que ocurrió con otras Entidades, porque su mantenimiento suponía unos costes fijos que se consideraron suprimibles por parte de la CARM. Al mismo tiempo, estábamos asistiendo a un notable distanciamiento entre Comunidad y Ayuntamiento de Murcia en muchas políticas.». 
Por otra parte, la cantidad de 270.422,13€ que también se abona a LATBUS en 2011 corresponde a la reunión de la Comisión Mixta de 28 de Diciembre donde se argumenta que hay un déficit de tarifa derivado de la simplificación correspondiente a 2010 que el ayuntamiento no ha asumido, ya que solo ha abonado $396.256 .81 €$ faltando $270.422,13 €$ por lo que la EPT decide asumir dicha cantidad autorizándose por Orden del Consejero de 30 de Diciembre de 2011.

Pero a pesar de ello, la EPT no ceja en su empeño de conseguir que el unibono regional fuese una realidad, y para ello el 1 de Mayo pone en marcha con una subvención de $20.536 €$ a la empresa «Autobuses de Lorca Bartolomé Muñoz S. L.», responsable de las concesiones urbanas en Lorca, y expresa un año más su deseo de extenderlo a Cartagena y el resto de municipios de la Región, hablando de «acuerdos de intenciones» con los municipios del área metropolitana, Molina, Santomera, Alcantarilla, Alguazas y las Torres de Cotillas. Por primera vez se contempla, aunque sea mediante un protocolo de trabajo que prevé la constitución de una comisión de trabajo, y cuando aún están incompletos los esfuerzos de unificación, la integración modal con el ferrocarril de vía estrecha.

También se otorga subvención a la empresa «Transportes Urbanos de Cartagena, S. A.» para la implantación del Unibono en Cartagena, si bien de la cuantía total se justificaron solo $20.780,87 €$, previéndose el resto de la subvención por importe de $29.219,13 €$ para años posteriores.

La EPT sigue también fomentando el uso del transporte público, en cumplimiento de sus objetivos más genuinos, y así se pone en marcha la implantación experimental del préstamo de bicicletas en el «laboratorio» de la universidad, se sigue con la representación de la obra teatral de «El autobús», se edita una nueva edición del atlas del transporte, se reparten libros en el transporte público el día del libro, y se participa como todos los años en la semana de la movilidad. La EPT se integra el 1 de Abril a la EMTA, después de que en 2010 fuera propuesta para su incorporación y admitida por el comité ejecutivo. Se intenta convocar de nuevo las ayudas del Plan «Papi» pero esta vez no hay liquidez en tesorería y se anula la convocatoria.

Las actuaciones de fomento del transporte público dan resultado con un segundo aumento consecutivo en el número de usuarios del transporte público a nivel regional, un aumento que es superior al registrado a nivel nacional.

GRÁFICO 1. EVOLUCIÓN TRANSPORTE VIAJEROS ESPAÑA/MURCIA 2011

ESPAÑA Viajeros transportados (miles) 2011

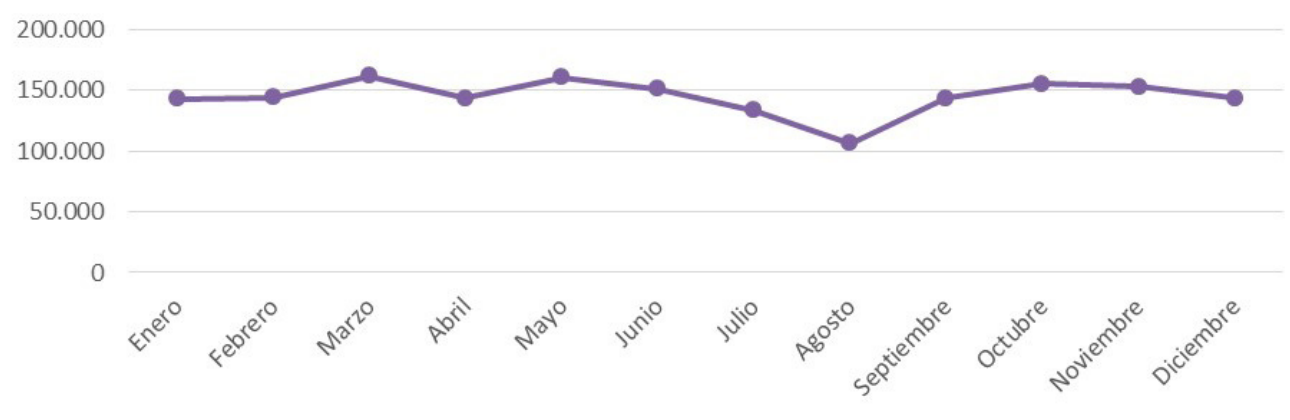

REGIÓN DE MURCIA Viajeros transportados (miles) 2011

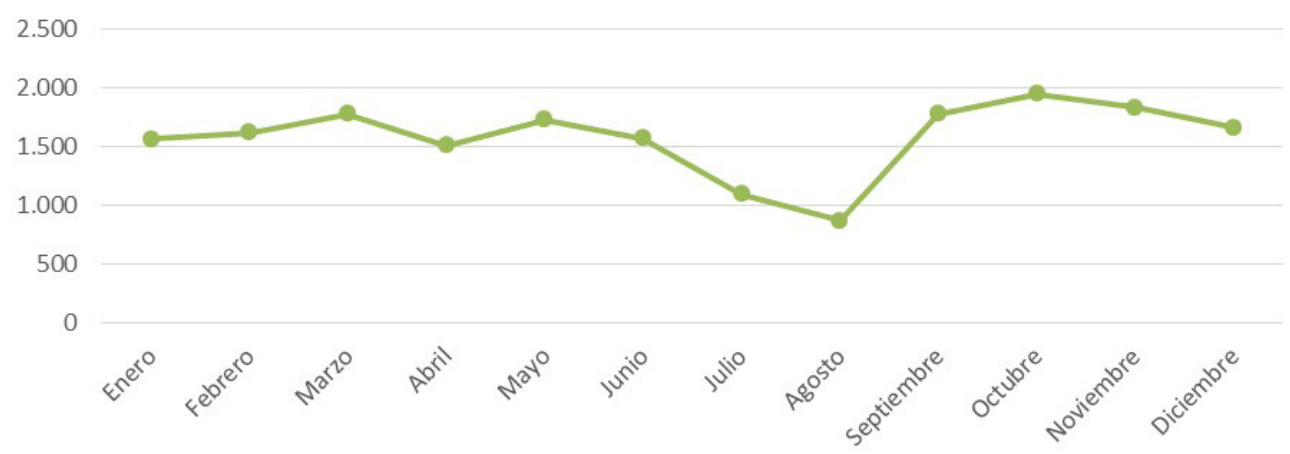

Fuente: INE. 
Se demandaba en el debate parlamentario que se diese voz a los representantes en materias relacionadas con el transporte en los órganos de gobierno de la EPT, incorporando representantes de urbanismo, medio ambiente, organizaciones sociales y económicas, y ello porque en la mayoría de estudios de transporte se entiende cuanto menos que las políticas públicas de movilidad deben estar relacionadas con la planificación territorial y urbana, por lo que como novedad se contrata un servicio de asesoramiento y consultoría en ingeniería e infraestructura de transportes para el estudio y análisis de los efectos de las actuaciones urbanísticas de los ayuntamientos que afecten al transporte.

La apuesta por las nuevas tecnologías sigue siendo prioritaria para la EPT y así, se presenta una nueva aplicación denominada «Urban Step» con la que ya cuentan otras ciudades en España, y que permite localizar la ubicación de paradas y el tiempo de llegada del autobús en tiempo real, sin embargo, esto no impide que se inicie la segunda fase del proyecto de paradas de última generación ampliándose el número de paradas que disponen de los servicios con objetivos similares a los que proporciona la aplicación, reservándose el Time: Bus para paradas de mayor afluencia.

Así mismo, se firma un protocolo con empresa de telefonía para la implantación del servicio NFC a fin de permitir el pago del unibono por móvil, un servicio que fue puesto en marcha de forma experimental en el 2010. Además, el proyecto «Ebus» para la prioridad semafórica inteligente iniciado el año pasado, fructifica en los municipios de Cartagena (21 de Febrero) y Lorca (28 de Marzo).

Aunque el presupuesto administrativo previsto para 2012 por la Ley Regional es de 4.169.500€, sensiblemente superior al previsto para 2011, el 2012 es un año de gran conflictividad para LATBUS, que a los problemas económicos con sus trabajadores que ya empezaron a plantearse en la primera fase de existencia de la EPT, sumaba los derivados de haberse quedado fuera del modelo de transporte municipal, con el impacto del tranvía compitiendo con sus líneas más prósperas, fundamentalmente la línea 39 del campus de Espinardo, aunque también con la 22 de Molina de Segura. El Ayuntamiento intentó despejar el camino para que el tranvía no sufriera merma de viajeros en los tramos donde coincidía, incluso con la total oposición del Alcalde de Molina, que se resistió en su momento a que los viajeros tuvieran que bajarse al llegar a la parada de entrada a Murcia para tomar a continuación el tranvía. Al final se respetó el paso de autobuses aún coincidiendo con el tranvía, si bien en el caso de la línea 39 se intentó que el itinerario no coincidiera con el paso del tranvía por la avenida Juan Carlos I.

Su exclusión del modelo de transporte municipal, no hizo sino agravar su delicada situación económica, que derivó en varias huelgas en las que se planteaba un constante conflicto entre LATBUS, con las administraciones regional y local. Si conflictuales eran las relaciones para la CARM con LATBUS, también lo son para el Ayuntamiento que ya da por amortizadas sus relaciones amistosas con el grupo, y prepara la licitación de sus concesiones cuya adjudicación a pesar de haberse anunciado para antes, no se produce sino a principios de 2013. Así pues, las relaciones en el triángulo de actores no son fluidas, y repercuten incluso en las oligarquías del partido que ostenta el gobierno autonómico y local, donde, con las elecciones recientes, se reproducen las luchas que tienen lugar en la arena del transporte.

La red por tanto se convierte en inestable, con multitud de interacciones a distintos niveles regional y local con LATBUS. Mientras la sintonía entre el Consejero y el Alcalde no existe, sí fueron fluidas en el segundo nivel de interacción entre el Director Gerente y el Concejal, como nos aseguró este último en la entrevista practicada. A esta red conflictual e inestable que propicia un inadecuado funcionamiento de las RIG, también alude la Concejal del grupo municipal «Izquierda Unida» en el Ayuntamiento de Murcia, Esther Herguedas, cuando se refiere a los factores intervinientes de la desaparición de la EPT, para señalar que:

"Los desencuentros con el Ayuntamiento de Murcia fueron fundamentales en la disolución de la entidad. Recordemos que el Ayuntamiento, puso en marcha el tranvía (que se comía el presupuesto municipal en transportes y fué un fiasco total al desaparecer las expectativas de desarrollo urbanístico de la zona norte). Además, ante los continuos problemas económicos de la empresa LAT, el Consistorio, con una torpe gestión por parte del concejal de transportes, sacó por su cuenta un concurso para el transporte en el casco urbano. El Ayuntamiento de Murcia abandonaba así a la mayor parte de la población del municipio, la residente en pedanías, y dejaba al Gobierno Regional como único responsable del transporte interurbano. Los recortes en forma de supresión de líneas (aunque eufemísticamente se hablaba de reorganizar el servicio) y la subida de precios no se hicieron esperar».

Con el movimiento de sillas derivado de las elecciones de 2011, parece que esta tendencia de alejamiento con el Ayuntamiento de Murcia de la que habla la Concejal, se atenúa con los nuevos responsables 
de la Consejería y de la EPT, Antonio Sevilla y Luis Lorente, si bien las políticas continuaban cada una en su dirección y descoordinadas por la ausencia de un proyecto global de transporte metropolitano, no ayudando el contexto de austeridad motivado por los coletazos de la crisis, y las continuas dificultades de LATBUS referidas por la Concejal. La sensación de un final cercano se apodera de la EPT durante este año 2012. Junto a las RIG apuntadas como principal variable explicativa de los malos presagios para la EPT, la Concejal Herguedas deja entrever que la crisis fue una variable interviniente en su desaparición:

"En cuanto al trabajo que tendría que haber realizado esta entidad y que ya hemos comentado (planificar, coordinar, intermodalidad, billete único, movilidad sostenible) nada se hizo en 6 años, y nada se iba a hacer al llegar la crisis. No tenía sentido mantener una entidad en estas condiciones.».

Pero además la red se convierte en conflictiva porque falta acuerdo en los problemas y sus soluciones, y porque no se busca el bien común, existiendo desacuerdo en al planteamiento del problema y también en la forma de resolverlo, ya que mientras el Ayuntamiento no atiende a las demandas de LATBUS y sigue adelante con la decisión de no renovar la concesión, la empresa acude a la CARM que se muestra más receptiva a encontrar una solución mediante nuevas aportaciones.

TABLA 1. SUBVENCIONES A OPERADORES OTORGADAS POR EPT 2012

\begin{tabular}{|c|c|c|c|}
\hline BENEFICIARIO & DESCRIPCIÓN & $\begin{array}{l}\text { IMPORTE } \\
\text { SUBVENCIÓN } \\
\text { PENDIENTE }\end{array}$ & COMENTARIO \\
\hline LATBUS & $\begin{array}{l}\text { Contrato-Programa común a las concesio- } \\
\text { nes MUR } 092 \text { y } 093 \text { por el que se esta- } \\
\text { blece la implantación del Sistema Tarifario } \\
\text { Simplificado, de fecha 3-12-2010. Anuali- } \\
\text { dad } 2012 \text {. }\end{array}$ & $1.860 .655 €$ & $\begin{array}{l}\text { Justificada por el beneficiario el } \\
\text { 18-12-2012. El 19-6-2013 se infor- } \\
\text { ma favorablemente aprobar me- } \\
\text { moria justificativa. }\end{array}$ \\
\hline LATBUS & $\begin{array}{l}\text { Contrato-Programa común a las conce- } \\
\text { siones MUR } 092 \text { y MUR } 093 \text { por el que } \\
\text { se establece la implantación del Sistema } \\
\text { Tarifario Eficiente, de fecha 15-10-2012. }\end{array}$ & $920.564 €$ & $\begin{array}{l}\text { Fecha fin de justificación 1-2-2013. } \\
\text { El } 27-5-13 \text { se informa favorable- } \\
\text { mente aprobar memoria justifica- } \\
\text { tiva. }\end{array}$ \\
\hline $\begin{array}{l}\text { TRANSPORTES } \\
\text { URBANOS DE } \\
\text { CARTAGENA, } \\
\text { S. A. }\end{array}$ & $\begin{array}{l}\text { Convenio de Colaboración para el fomen- } \\
\text { to y mejora del transporte público universi- } \\
\text { tario durante } 2011 \text { y } 2012 \text { en el municipio } \\
\text { de Cartagena. }\end{array}$ & $75.000 €$ & $\begin{array}{l}\text { Fecha fin de justificación: } 31-1- \\
2013 \text {. el } 27-5-2013 \text { se informa } \\
\text { favorablemente aprobar memoria } \\
\text { justificativa. }\end{array}$ \\
\hline $\begin{array}{l}\text { AUTOBUSES } \\
\text { URBANOS } \\
\text { BARTOLOMÉ } \\
\text { MUÑOZ, S. L. }\end{array}$ & $\begin{array}{l}\text { Convenio de Colaboración para el mante- } \\
\text { nimiento durante el ejercicio } 2012 \text { del sis- } \\
\text { tema tarifario simplificado en los servicios } \\
\text { de transporte público regular de viajeros } \\
\text { por carretera prestados en el municipio } \\
\text { de Lorca. }\end{array}$ & $13.000 €$ & $\begin{array}{l}\text { Fecha fin de justificación: } 31- \\
1-2013 \text {. Con fecha 9-5-2013 la } \\
\text { DGTP requiere al beneficiario } \\
\text { para que presente la justificación. } \\
\text { Según alegaciones la DGTP ini- } \\
\text { ciará expediente de reintegro. }\end{array}$ \\
\hline TOTAL & & 2.869.219€ & \\
\hline
\end{tabular}

Fuente: Informe de auditoría EPT 2012.

Así pues, LATBUS recibe durante 2012 un importe de $3.082 .678,15 €$ en concepto de subvenciones, de los cuales, $1.860 .655,44 €$ corresponden a las cantidades previstas para 2012 del unibono municipal derivado de la comisión mixta del contrato programa de 3 de Diciembre de 2010, 301.459,20€ corresponden a la liquidación también del contrato programa correspondientes a 2011, y $920.563,51 €$ se destinan a la denominada implantación del Sistema Tarifario Eficiente de 15 de Octubre, o también conocido en los medios de comunicación y opinión pública como «tarifazo» con el que se pone fin a la huelga, y se hace patente el tono concertador en la actitud de la CARM frente al perfil activista o regulador del Ayuntamiento en sus interacciones con el operador. 
En Julio se celebra el que sería uno de los últimos consejos de administración de la Entidad, antes de su disolución, y el Consejero hace un balance «generalmente bueno» de la situación transcurrida hasta la fecha. Como también se deduce del informe de gestión, en un contexto de recientes cambios y crisis económica, la EPT ya no goza de la frenética actividad de otros años, y se convierte en un órgano de marcado perfil burocrático que se limita a hacer las tareas que se le asignan. $Y$ así se destacan aspectos como el número de quejas tramitadas o el número de autorizaciones de transporte escolar o de transporte de obreros que se han otorgado. Estas tareas estaban tan identificadas con la «gestión cotidiana» y tan «interiorizadas» por la «caja negra» de la DGTP que las tramitaba antes de la creación de la entidad, que puede considerarse como uno de los detonantes en los que el sentimiento de rechazo de los funcionarios hacia la externalización que conllevaba la EPT, se hizo más patente.

También se destaca por el Consejero la «eficiente gestión presupuestaria del $94 \%$ » llevada a cabo. Hay que destacar sin embargo que según se ha podido comprobar, en el informe del Tribunal de Cuentas referido a 2012, "se pone de manifiesto, el bajo porcentaje de autofinanciación de las empresas públicas regionales y la consiguiente elevada dependencia financiera que presenta el sector público empresarial» respecto a la Administración Autonómica. En el caso de la EPT, como hemos podido observar, la dependencia con la Consejería es prácticamente total. Esto una vez más se traduce en la falta de liderazgo «distintivo» de la EPT respecto al de la Consejería con la que está a veces confundida e inescindiblemente unida, lo que es entendible por razones innatas a su propia creación, pero además supone que es percibida por el resto de actores como una prolongación de la Consejería, que es quien verdaderamente adopta las decisiones en un año difícil en el que está en juego la supervivencia económica de la operadora más importante por el número de viajeros, LATBUS.

La falta de coordinación en el transporte interurbano y urbano es en opinión del presidente de la organización de consumidores y usuarios CONSUMUR una de las razones por las que se decide crear la EPT, pero además el objetivo de coordinación de las corporaciones locales que se atribuye a la entidad, no fue precisamente un ejemplo a seguir, como se puede observar en la contestación a las preguntas formuladas.

- ¿Considera que las relaciones entre las administraciones intervinientes explican la decisión de crear la EPT? ¿Cree que esas relaciones influyeron en su posterior desaparición?

"Entiendo que tanto en un caso como en otro, la respuesta es sí. Se trataba de coordinar el transporte urbano e interurbano y necesariamente requería de la clara voluntad (política, sobre todo) para que ello fuera posible. Igualmente, es lógico que el impulso de dichas Administraciones son, al mismo tiempo, quienes empujan con sus decisiones y falta de credibilidad, ganada a pulso, la desaparición de la EPT.».

- ¿Fue la EPT el instrumento adecuado para mejorar la coordinación de las corporaciones locales en materia de transportes?

«No cabe la menor duda, que no fue así. Disponían de más recursos humanos y medios económicos que superaban realmente las expectativas que de ella se esperaba. Una fuente de inspiración de lo que no debe hacerse en materia de (des)coordinación de un servicio público, precisamente con gestión privada.».

La idea de la necesidad de una gestión pública del servicio de transporte también es enfatizada por el alcalde de Molina del Segura en esa época, Eduardo Contreras: "Hay temas que debe controlar directamente la administración como son las políticas de transporte, ya que cualquier problema vinculado con el servicio del autobús, como la frecuencia, puntualidad o calidad del servicio es demandado directamente a los representantes de las administraciones locales».

La empresa considera que las pérdidas de $20.000 €$ diarios que según sus estimaciones sufría la explotación, no estaban siendo compensadas por las distintas administraciones, que venían demorando la aprobación del Plan de Viabilidad desde principios de 2012 de manera que tras un tenso e interminable intercambio de escritos entre el Director de la EPT, y los dueños del grupo LATBUS, Ángel Jiménez y José Luis Sánchez, este último también con un poder reforzado como Presidente de la asociación mayoritaria de empresas de transporte de viajeros, FENEBUS-Murcia, acuerdan suspender el contrato programa de simplificación tarifaria de 3 de diciembre de 2010, y aplicando consecuentemente el cuadro vigente con anterioridad a 2010, que con las pertinentes actualizaciones, se traduce en el impopular aumento de tarifas que llega a alcanzar los $2,15 €$ desde los $1,35 €$ que se pagaba por el billete de líneas coordinadas. 
El aumento de hasta casi un $60 \%$ del precio del billete era el precio que había que pagar por la descoordinación y por el fracaso de las RIG entre los actores políticos y privados que participan en la política de transporte. La reacción de los actores político institucionales no es la misma. Las relaciones conflictuales en el triángulo de actores no desaparecen. LATBUS está convencida de que su problema económico es el problema de las instituciones, pues en su opinión se trata de mantener un servicio no retribuído ante la ausencia de una decisión política que permita aliviar la excesiva carga económica que soporta, y ante la indiferencia del Ayuntamiento presenta más de mil firmas en las que los usuarios reclaman que se establezcan las bonificaciones al billete de autobús, dando prioridad a este servicio. Las firmas se presentan a la EPT y también al Alcalde, aunque en el escrito se indica que considera al Ayuntamiento como el principal destinatario de sus reivindicaciones, «dado que su colaboración resulta fundamental para proceder a atender las peticiones ciudadanas».

La EPT, sin embargo, tiene interés en regularizar la situación por lo que finalmente cede y acuerda dar por resuelto el contrato programa de 2010 , si bien para, como indica en su informe, «establecer un nuevo sistema de títulos bonificados que facilite el acceso a un servicio tan esencial como es el transporte público en autobús, (...) a los efectos de reducir el coste que para la administración pública y las empresas concesionarias supone el mantenimiento de este servicio en el actual contexto económico». Es el sistema tarifario que ahora se denomina «eficiente», que entra en vigor el 8 de Octubre y que consiste en otorgar nueva subvención de $920.564 €$.

Pero este apoyo económico no viene solo. El Plan de Viabilidad señalaba que además de un aumento de tarifas, era preciso acometer la reordenación del mapa de concesiones, y por ello la EPT afronta la puesta en marcha del Plan de Reestructuración de Líneas, un plan que tiene por objeto mejorar la eficiencia y eficacia del transporte, "evitando solapamientos y duplicidades» entre líneas.

El Plan es contestado también desde la oposición municipal y en el Pleno celebrado con ocasión de su aprobación por la EPT, el grupo socialista, al considerar que supone una lesión del derecho fundamental a la «accesibilidad y a la libertad de movimiento de personas» plantea una moción para:

- "Instar a la CARM a que urgentemente adopte las medidas oportunas para restablecer el transporte público en aquellos barrios o pedanías que han perdido este servicio tras la puesta en marcha del Plan de Optimización de Recursos del Transporte Público.

- En caso de que la CARM no ofrezca una solución a esta situación urgente, que el Ayuntamiento de Murcia asuma con sus recursos el servicio de transporte público en los barrios y pedanías que se han quedado aislados (...).».

El último consejo de administración de la EPT se celebra el 6 de noviembre de 2013 y en él se aprueba por unanimidad realizar la propuesta a la CARM para la extinción de la EPT conforme su normativa, y también se aprueba la constitución y composición de la comisión liquidadora de la EPT. El 27 de diciembre, el Presidente de la CARM aprueba la supresión de la EPT que surte efectos el 1 de enero de 2013. No se hacen esperar las opiniones acerca de las razones de su desaparición, pero en casi todos los entrevistados aparece la variable de las RIG como una de las variables explicativas.

Incluso el Director adjunto de LATBUS también alude directamente a la «desgastada y hostil relación de administraciones y concesionarios» y al rechazo de los entes municipales a la cesión de competencias a niveles de gobierno superiores, como probables causas de la supresión de la EPT, y así lo expresa en un artículo que publica pocos días después del consejo de administración en el que se acuerda la disolución.

La mención a las RIG como causa de la desaparición de la EPT es muy clara en las entrevistas realizadas a los diputados Oñate, Navarro, y Moltó, aunque este último las hace extensivas a las relaciones con los operadores privados. El diputado Navarro se refiere en la entrevista a «la impericia y la incapacidad para el diálogo y el entendimiento» como otras variables que también pudieron influir en su desaparición, pero en el fondo se trata de consecuencias de las RIG. Además destaca "(...) la soberbia institucional de los promotores y el equipo gobernante, incapaz de recoger y hacer participar singularmente en la constitución del proyecto a agentes sociales tales como las organizaciones vecinales, grupos ecologistas o sindicatos, negándoles una auténtica participación institucional, profesional y social en el proyecto.».

Por su parte el diputado Oñate, hace especial énfasis en el tranvía como detonante de esas malas relaciones: "sé que hubo tensiones importantes sobre todo con el municipio de Murcia sobre qué cantidad y qué líneas se bonificaban o se dejaban de bonificar, y ya digo, la irrupción del tranvía que rompe todas las esta- 
dísticas económicas del sistema de transportes porque aquello vino con un sobrecoste, vino además con una entrada que para hacerlo entrar con suavidad como recordará durante unos meses era gratis, y con un canon importantísimo que lo seguimos pagando en la actualidad, un canon de la bonificación del transporte que hace seguramente que en el municipio de Murcia se quieran recoger pues cuantas más ayudas mejor porque creo recordar que hablábamos en aquellos tiempos de 9 millones $€$ de canon que era una cantidad...con un peso decisivo sobre el presupuesto municipal muy significativa en el gasto corriente... una "herida" importante.».

Ambos aluden a la improvisación que también caracterizó la estrategia de la EPT, y esa impericia de la que habla del Sr. Navarro, se concreta en algo que se constató con el análisis de los debates parlamentarios, la ausencia de norma legal previa habilitante que permitiese sentar las bases para el posterior funcionamiento de la EPT, a la que se refiere en la entrevista. Algo que también destaca el Sr. Oñate, que se refiere a que "(...) se crea el órgano antes que la función...se crea la empresa pero no hay un marco legislativo regional» y esta circunstancia está también en la forma en que terminó con la entidad «(...) si ha sido fácilmente sustituible entre comillas es porque la falta de una legislación que amparara la existencia del propio órgano y le diera unas competencias, pues de inspección, de ejecución (...)» de manera que si hubiese existido esa regulación previa «la supresión de esa entidad tendría que haber sido un problema grave, y sin embargo se disolvió de un plumazo (...)».

EI Presidente de Consumur alude igualmente a las RIG, aunque cuando se pronuncia sobre la eficacia de la EPT para el transporte y afirma que «Ha resultado ser un instrumento incapaz de rentabilizar, a pesar de todos los medios con los que contaba. Incompetente para dar respuesta a los graves problemas de un transporte de calidad en la región. Incapaz de solucionar y coordinar adecuadamente los transportes urbanos e interurbanos en un municipio como Murcia que acapara más del $25 \%$ de la población regional. Incapaz de gestionar un transporte metropolitano, así como de influir en la nefasta política que un ayuntamiento como Murcia desarrolló con la implementación de un tranvía innecesario y que solo resulta beneficioso para una empresa».

A nivel local las opiniones no son diferentes, incluso por encima de opciones políticas. Y así la concejal Herguedas habla de la cuestión competencial, un asunto relacionado con las RIG, y afirma que «(...) es fundamental (...)» si bien «Finalmente, (...) se resolvió mediante una Ley (2015) una vez disuelta la entidad», mientras el concejal de transportes es más claro cuando afirma sin duda que las RIG influyeron, como ya indicamos. El Sr. Castillo sólo se refiere de manera tangencial a la crisis económica como variable interviniente, y en especial la matiza refiriéndola a «falta de dotación económica para su funcionamiento»: «(...) durante mi mandato empezaba a asomar la crisis económica, pero no creo que influyera tanto la crisis en su desaparición como la falta de dotación económica para su funcionamiento. (...) las concesiones urbanas siguen hoy en día subvencionándose, (...)». También menciona el tranvía como otra variable a tener en cuenta: "considero decisiva la irrupción del tranvía, un medio de transporte que costaba al Ayuntamiento 10 millones de euros anuales, y que había que financiar sin dejar de lado a las concesiones urbanas, de manera que el tranvía absorbía casi todas las posibilidades de financiación».

Por el contrario, tanto desde dentro de la EPT como desde la perspectiva del beneficiario de sus políticas, la opinión es bien distinta, y la responsabilidad en su desaparición recae en motivos económicos, concretamente en el caso del Sr. Pacheco se alude a la falta de tiempo y presupuesto, motivada esta última por las reducciones del gasto público, y en el caso del Director Gerente de LATBUS, que aunque alude al «notable distanciamiento entre la CARM y el Ayuntamiento (...)» cuando se le pregunta por los factores que influyeron en su desaparición responde: "La crisis económica, que se llevó por delante varios Entes Públicos de la Región de Murcia.».

Resulta llamativo que mientras todos los actores entrevistados destacan con mayor o menor intensidad el papel que las RIG jugaron en la creación de la EPT, a la hora de explicar su desaparición haya diferencias entre los actores político institucionales, que también creen que las RIG podría ser una variable explicativa, y entre los actores privados, que consideran que apuntan a la crisis y la austeridad presupuestaria como motivos de su desaparición. Es cierto que este motivo también es aludido por el técnico de la EPT entrevistado, aunque es comprensible en atención a su perspectiva externa respecto al triángulo de actores en el que tuvieron lugar las RIG.

El presidente de FENEBUS destaca en cuanto a la creación que:

«El origen estuvo en la armonía de las relaciones de las diferentes administraciones para crear un nuevo organismo que coordinase las competencias en materia de transporte. Una prueba es que el alcalde de Murcia era el Vicepresidente de la EPT.». 
Es decir, admite el protagonismo de las RIG, pero cuando habla de la desaparición señala que:

«Después de muchos años de conversaciones entre las Administraciones y el Sector, se acordó que Murcia debía contar con una estructura de gestión del transporte a similitud de lo que ya estaba ocurriendo en otras importantes zonas de nuestro País y en donde se estaba demostrando que el transporte funcionaba mucho mejor.».

En esta misma línea el técnico de la EPT preguntado por si las RIG explican la creación de la EPT señala que:

"No influyeron en su posterior desaparición. Las relaciones entre las administraciones que conformaban la EPT, una vez finalizado el proceso de adhesión de todos los municipios de la Región, eran buenas. Todos los Ayuntamientos de la Región querían colaborar en una mejor coordinación y gestión del transporte público de viajeros en autobús que se ejercía bajo sus competencias y eran sabedores del aspecto positivo que para ello suponía formar parte de la EPT, especialmente por lo que al aspecto económico se refería, ya que, la Comunidad Autónoma de la Región de Murcia, tenía más capacidad para dotar de presupuesto a esta Entidad y, con ello, favorecer la inversión en mejora del transporte público de viajeros en autobús de los diferentes municipios integrados en la EPT».

Por el contrario los actores político institucionales son unánimes en la opinión contraria, incluso al margen de cuestiones de partido, pues la opinión del propio concejal de transportes es clara:

"Sin duda, de hecho se llegó a un acuerdo con la totalidad de los Ayuntamientos de la Región, sin embargo el Ayuntamiento de Murcia fue el último en adherirse por su resistencia a ceder competencias en las concesiones urbanas que gestionaba. En el momento en que me hago cargo de la Concejalía en 2007, ya está puesto en marcha el tramo cero "experimental" del tranvía, y el municipio apostaba claramente por el tranvía como modelo en torno al que estructurar el sistema de transporte urbano.

Claramente esas relaciones influyeron en la desaparición. Como digo, la integración de todos los municipios se produjo formalmente pero no de forma efectiva, ya que no se produjo la cesión de competencias de las líneas urbanas a favor de la EPT».

También la opinión de los usuarios del transporte, a través de su Presidente, Roberto Barceló Vivancos va en la misma línea de explicar tanto la creación como la desaparición con base a las RIG:

«Entiendo que tanto en un caso como en otro, la respuesta es sí. Se trataba de coordinar el transporte urbano e interurbano y necesariamente requería de la clara voluntad (política, sobre todo) para que ello fuera posible. Igualmente, es lógico que el impulso de dichas Administraciones son, al mismo tiempo, quienes empujan con sus decisiones y falta de credibilidad, ganada a pulso, la desaparición de la EPT».

Pero la opinión del diputado regional y posteriormente concejal Alfonso Navarro, es todavía más rotunda cuando señala que "Sin ninguna duda (...) tanto en la decisión de su constitución (EPT) como en el proceso que dio lugar a su posterior desaparición, jugó un papel importante la relación (desacuerdo o discrepancias) interinstitucionales, y su definitiva gestión por parte de quien mayor responsabilidad tenía, que era la Administración Regional.». Por otra parte, su compañero de partido, el también diputado regional Francisco Oñate, dejaba entrever el papel secundario de la crisis económica en la desaparición de la EPT cuando alude a "la sensación de despilfarro de las administraciones y eso en muchos casos tiene una traducción meramente aritmética, es decir, cuantos organismos... cuanto personal... y efectivamente la empresa del transporte forma parte... pudiera ser uno de los sacrificios, una de las ofrendas que hiciera el gobierno, que es una ofrenda estadística, para no sacrificar otros organismos en los que pudiera tener más interés (...)» para destacar más adelante que «hubo organismos, muchos que todavía hoy sobreviven y son menos necesarios».

La existencia de una autoridad común de transporte se considera una importante necesidad por parte de Eduardo Contreras, alcalde de Molina, a pesar de la experiencia fallida: «Es necesaria una Autoridad común de transporte, pero debe dotarse presupuestariamente desde la Comunidad Autónoma, aunque los municipios tengan que aportar, pero debe organizarse desde arriba». 
Las RIG son uno de los rasgos característicos de la nueva gobernanza, que tiene una dimensión política, centrada en la participación de actores ajenos a la administración en la toma de decisiones públicas, y una dimensión administrativa, en la que tiene lugar la coproducción de los actores. La Implementación conlleva la creación de estructuras institucionales diseñadas como instrumentos para la distribución de recursos en las que existen áreas específicas de carácter estratégico cuya importancia se define por el porcentaje de gasto público, pero en las que también existen las dimensiones política y burocrática.

El análisis de las RIG deja claro que ante una cuestión problemática se produce una alineación partidista que resulta ser el factor decisivo al optar por una alternativa u otra, en consecuencia, las RIG están estrechamente ligadas a las relaciones de poder, de «quién manda».

\section{DISCUSIÓN: ¿POR QUÉ FALLÓ LA POLÍTICA DE TRANSPORTE EN LA REGIÓN DE MURCIA?}

\subsection{Buena estrategia de comunicación pero consenso insuficiente}

La implementación de la EPT contó con una estrategia mediática bien diseñada con el fin de disminuir la oposición de los agentes participantes y de los grupos políticos, aumentando la aceptación y el consenso en torno a sus objetivos. Estuvo bien diseñada, pero sólo eso, pues puede observarse en las entrevistas cómo la estrategia no se correspondió con una sensación de confianza en la necesidad de su creación, con cierto recelo entre los funcionarios de la DGTP, entre los «street level burocrats» encargados de lograr sus objetivos, o cuando menos en algunas de las herramientas de que se dotó a la EPT para la consecución de sus fines. Realmente la EPT estuvo rodeada de poca convicción en la necesidad de su creación, con resistencias al cambio desde las estructuras institucionales, sobre todo a la cesión de competencias.

A ello hay que unir la escasa participación de los municipios alejados del área metropolitana de Murcia.

Por otra parte, la implementación «heredó» un déficit importante de participación en la fase de formulación, con la ausencia de las organizaciones sindicales en el proceso de creación, lo que se tradujo en una fragilidad en el proceso de evolución hacia la consecución de sus objetivos. La identificación de los problemas por los actores con intereses en el proyecto, aunque conlleve dar un paso atrás que pueda entenderse como un obstáculo, se traduce en un reforzamiento del consenso que hace que la implementación tenga más posibilidades de éxito. ¿Podría estar este déficit entre las razones para la dificultad de cumplir con el objetivo de «proponer al Consejo de gobierno la elaboración del Plan de Transporte de Viajeros» que no llegó a ver la luz en los años de existencia de la EPT?

\subsection{Ausencia de una planificación estratégica de transportes}

Toda estrategia de implementación conlleva la necesidad correlativa de realizar previamente una planificación estratégica correctamente diseñada, que fundamente un proyecto global de transportes, y así ha sucedido a nivel comparado en otras experiencias a las que se ha hecho referencia, como el Plan de Transportes del gobierno valenciano, que vincula a los municipios actuando el gobierno autonómico de forma subsidiaria. Pero además, como hemos indicado, la necesidad de contar con un plan de transportes ha sido históricamente una constante para los distintos gobiernos a nivel regional. Sin embargo, los antecedentes en el año 2000 con la elaboración del Plan Integral de Viajeros de la Región de Murcia, o con el Plan Director de Transportes del año 1984, no han servido para incentivar la elaboración del anhelado plan durante los años de existencia de la EPT y ello a pesar de ser una de las funciones que la Ley de creación atribuye al Consejo de Administración.

\subsection{La pretendida flexibilidad en su creación se convierte en improvisación}

Este fallo de implementación podría ser una consecuencia del anterior, y también de la inexistencia de una labor previa de estudio y análisis. En el debate político vimos cómo se procedió a la creación de la EPT sin que anteriormente existiera un grupo de trabajo que estudiara los problemas de coordinación del transporte regional, como sin embargo sí existió en el caso asturiano, y sin que las cuestiones como las funciones y tareas a ejercer por cada nivel gubernamental, estuviesen claramente delimitadas por medio de la existencia de una normativa previa, siendo trascendental para una materia como el transporte en la que existe una comunidad de fines derivada de la concurrencia competencial de varios entes. ¿Bajo qué amparo legal se 
incluyeron las competencias en un ente autonómico para decidir sobre cuestiones referentes a concesiones de titularidad municipal?

Esto pudo entenderse al principio como una pretendida flexibilidad que dotaba de cierta agilidad a su funcionamiento, pues se entendía que la relación causa efecto entre poner en marcha una autoridad común de transportes y el aumento de las estadísticas de utilización del transporte público iba a ser inexorable, pero, cuando se profundiza en la modernización de concesiones sin que se haya producido el traspaso de funciones desde la DGTP, cuando se persigue la unificación tarifaria sin que exista un proyecto global para el transporte regional, o cuando en cuestión de meses y de forma desprogramada se promueve la adhesión de ayuntamientos ajenos a los ámbitos de actuación metropolitanos, y a los núcleos de concentración de las demandas de transporte, lo que se transmite es cierta sensación de improvisación.

\subsection{Carencia de medios y recursos materiales e inexistencia de representación ponderada económicamente en sus órganos de gobierno}

En la política de transportes, la observación empírica del estado en movimiento y en concreto la creación de un organismo especializado como la EPT, nos da una idea de cómo la CARM se propone intervenir para fomentar el uso de transporte público, pero esa dimensión cualitativa debe ir acompañada de la cuantitativa, de los medios o recursos. Desde dentro de la EPT se admite que no se dotó con los suficientes medios a la entidad.

Pero además la creación de una nueva organización con una estructura plural en la dirección ejecutiva, integrada por los 45 ayuntamientos adheridos, es algo más que la mera creación de un aparato burocrático y supone una clara invitación a que esa multiplicidad de actores vean correspondida su participación mediante una representación económica ponderada. La implementación conlleva determinar los medios más directos para alcanzar los objetivos, y centrar la atención no tanto en la creación de la estructura organizativa para ejecutar el programa como en su funcionamiento.

¿Acaso se recogió en los Estatutos de la EPT, siquiera sea potencialmente, pues no se llegaron a elaborar, que el voto de Ayuntamientos como el de Murcia, sería ponderado como compensación a su baja representatividad? EI CES ya indicó en 2005 que no se consideraba oportuno fijar la participación de Ayuntamientos y CARM en la Ley de presupuestos sino que sería más adecuado hacerlo en los Estatutos, y aunque hubo tiempo para ello, no se llegaron a aprobar en los seis años de existencia.

¿Es razonable equiparar el voto de una de las áreas metropolitanas de mayor envergadura a nivel nacional como la de Murcia, con el de Ayuntamientos correspondientes a núcleos o subsistemas urbanos dispersos sin servicio de transporte y alejados de las áreas supralocales de prestación?

\subsection{Mal funcionamiento de las RIG en una red de actores conflictual}

Como hemos indicado al analizar la evolución de la EPT, la apuesta del ayuntamiento de Murcia por un tranvía localista en lugar de metropolitano, el excesivo protagonismo de las relaciones políticas con la exigencia de que la CARM participara al $50 \%$ en su costosa financiación para aliviar la deuda municipal, supuso un punto de inflexión en las RIG entre los actores autonómico y local, y los problemas económicos del operador principal de líneas interurbanas y urbanas, con una clara dependencia institucional y acostumbrada a que el poder de decisión estuviese en pocas manos, pero a su vez clave en la consecución de objetivos primordiales para la EPT como la unificación tarifaria, convirtió a la red de actores en una red conflictiva, que a la postre se tradujo en la principal brecha de implementación que dio al traste con las expectativas generadas con la EPT.

Dos son los mensajes claros que pueden derivarse de la experiencia de la EPT: el primero, que la Ley por sí misma no es requisito suficiente para garantizar el éxito en la implementación de una política pública, y menos aún cuando es una norma que nace debilitada sin un proyecto global y una norma de base que la respalde y la segunda, que la organización pública, instrumento para la implementación, no se encuentra aislada de su entorno, y del juego de las RIG en la red de actores responsables de esa implementación. En un contexto como el actual en el que bajo criterios de gobernanza el Estado es necesario pero no suficiente, las Administraciones Públicas tienen el reto de responder a los principios constitucionales de los que se deriva el derecho a la movilidad en las aglomeraciones urbanas, en cuanto que servicio esencial a la ciudadanía, desde un prisma en el que se fomente la participación de todos los actores en el proceso de decisión pública. 
Por tanto las RIG no solo se constituyen como una variable explicativa de la creación de la EPT sino que además atendiendo a su evolución, los problemas de funcionamiento en la red de actores diseñada, contribuyen a explicar igualmente su desaparición. En la investigación realizada se ha puesto de manifiesto que la creación, funcionamiento y desaparición de la EPT tuvo una gran relevancia y repercusión social, y puede considerarse como un caso típico que después de ser analizado con la suficiente profundidad permite afirmar que la modernización, mejora y eficacia de un sistema de transporte depende de la creación de una autoridad común, que, superando las barreras competenciales existentes, permita la actuación coordinada de los actores y el adecuado funcionamiento de las RIG.

La modernización del sistema de transporte público mediante la creación de una autoridad común sigue siendo una preocupación actual, formando parte de la agenda política en la actualidad. En este sentido, en Marzo de 2018 la Mesa del Transporte constituida por el Ayuntamiento de Murcia para afrontar la transformación del modelo de transporte ha planteado la posibilidad de asumir la titularidad de todas las líneas que circulan en el municipio, tanto en el casco urbano como en pedanías, mejorando la eficacia del modelo de transporte dotándolo de la necesaria coordinación que posibilite la anhelada unificación tarifaria.

\section{RESULTADO DE ENTREVISTAS REALIZADAS A ACTORES}

Como se indicó en el apartado de metodología referente al tipo de datos y técnicas a utilizar, se han realizado entrevistas en profundidad y semi-estructuradas a diversos actores implicados que han sido seleccionados por su interés en relación con los objetivos de la investigación.

Las entrevistas en profundidad se realizaron mediante la remisión del guión de preguntas contenido en el apartado 3.4, y fueron respondidas por escrito en la mayoría de los casos, y en menor medida de forma oral. También se realizaron entrevistas semi-estructuradas. En unos casos y otros se considera oportuno y de interés para el lector, facilitar el acceso a la transcripción íntegra de las mismas haciendo clic aquí: https:// www.dropbox.com/sh/ovf1lokowffotvl/AAB2SPyOwAtGK7V_ICn-BLZKa?dl=0.

\section{BIBLIOGRAFÍA}

ANDUIZA PEREA, E. (2009): "Metodología de la Ciencia Política", en Cuadernos Metodológicos, núm. 28. Madrid: CIS, 2. ${ }^{a}$ ed. revisada.

BAILEY, S. and MOSHER, E. (1968): The Office of Education Administers a Law. Syracuse (Nueva York): Syracuse University Press.

CHAQUÉS BONAFONT, L. (2004): Redes de políticas públicas. Madrid: Centro de Investigaciones Sociológicas.

DERTHICK, M. (1970): The influence of federal grants: Public assistance in Massachusetts. Harvard University Press.

FROMAN, L. A. (1968) "The categorization of policy contents" en RANNEY, A. (ed.): Political Science and Public Policy. Chicago: Markham.

GROSS, N., GIACQUINTA, J. B. and BERNSTEIN, M. (1971): Implementing Organizational Innovations. New York: Basic Books.

HERNÁNDEZ MARTÍN, M. (1988): "El Transporte en España: notas sobre la nueva regulación del subsector de transporte público de viajeros", en Moneda y Crédito, núm. 186, págs. 23-39.

HJERN, B. and PORTER, D. O. (1981): "Implementation structures: a new unit of administrative analysis", en Organization studies, vol. 2, núm. 3, págs. 211-227. DOI: https://doi.org/10.1177/017084068100200301.

KAUFMAN, H. (2017): The limits of organizational change. Routledge. DOI: https://doi.org/10.4324/9781315132945.

LOWI, T. (1972): "Four systems of Policy, Politics and Choice", en Public Administration Review, vol. 32, núm. 4, págs. 298-310. DOI: https://doi.org/10.2307/974990.

MENZEL, D. (1981): "Implementation of the federal surface mining control and reclamation act of 1977", en Public Administration Review, vol. 41, núm. 2, págs. 212-219. DOI: https://doi.org/10.2307/3110076.

MOLNAR, J. and ROGERS, D. L. (1979): "A comparative model of interorganizational conflict", en Administrative Science Quarterly, núm. 24, págs. 405-425. DOI: https://doi.org/10.2307/2989920.

CRUZ, C. N. (1999): "El Reto Público de la Implementación" en Estudios Políticos, núm. 21, págs. 113-135.

O'TOOLE, J. R., LAURENCE, J. (2000): "Research on policy implementation: Assessment and prospects", en Journal of public administration research and theory, vol. 10, núm. 2, págs. 263-288. DOI: https://doi.org/10.1093/ oxfordjournals.jpart.a024270.

PRESSMAN, J. and WILDAVSKY, A. (1973): Implementation: How Great Expectations in Washington Are Dashed in Oakland. Berkeley: University of California Press.

SANTANA LEITNER, A. (2013): Fundamentos para la investigación social. Madrid: Alianza Editorial. 
SUNDQUIST, J. (1969): Making Federalism Work. Washington, D. C.: Brookings.

VAN METER, D. S. and VAN HORN, C. E. (1975): "The policy implementation process: A conceptual framework", en Administration \& Society, vol. 6, núm. 4, págs. 445-488. DOI: https://doi.org/10.1177/009539977500600404.

\section{RECURSOS VIA WEB}

Blog de Modernización de la Administración Pública. http://www.modernizacionadministracionpublica.blogspot.com.es.

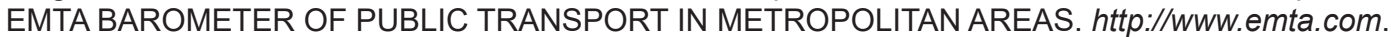

Página web del Ministerio de Fomento. Observatorio Transporte Viajeros por Carretera. http://www.fomento.gob.es/NR/ rdonlyres/F667D69B-62F1-4ED2-A041-8FAD5F69C07D/109393/ObservatorioViajerosOfertayDemandaenero2012.pdf. Consejo Económico y Social de Murcia. http://www.cesmurcia.com/publicac_COM.htm.

European Commission. Eurostat.

EUROPA - Estadísticas y encuestas sobre la UE.

Urban mobility - Transport. $h$ ttp://www.eltis.org/index.php?id=13\&lang1=en\&study_id=4065.

Consejo Regional Estadístico. CREM - INFORMACIÓN ESTADÍSTICA ECODATA. 